Chapman University

Chapman University Digital Commons

Mathematics, Physics, and Computer Science Science and Technology Faculty Articles and Faculty Articles and Research Research

2015

\title{
Climate Change Impacts on Maize-Yield Potential in the Southwestern United States
}

\author{
Seung Hee Kim \\ Chapman University, sekim@chapman.edu \\ Jinwon Kim \\ University of California - Los Angeles \\ Robert Walko \\ University of Miami \\ Boksoon Myoung \\ Chapman University, bmyoung@chapman.edu \\ David Stack \\ Chapman University
}

See next page for additional authors

Follow this and additional works at: https://digitalcommons.chapman.edu/scs_articles

\section{Recommended Citation}

Kim, S.H., Kim, J., Walko, R., Myoung, B., Stack, D., Kafatos, M., 2015. Climate Change Impacts on Maizeyield Potential in the Southwestern United States. Procedia Environmental Sciences, Agriculture and Climate Change - Adapting Crops to Increased Uncertainty (AGRI 2015) 29, 279-280. doi:10.1016/ j.proenv.2015.07.210

This Article is brought to you for free and open access by the Science and Technology Faculty Articles and Research at Chapman University Digital Commons. It has been accepted for inclusion in Mathematics, Physics, and Computer Science Faculty Articles and Research by an authorized administrator of Chapman University Digital Commons. For more information, please contact laughtin@chapman.edu. 


\section{Climate Change Impacts on Maize-Yield Potential in the Southwestern United States}

\section{Comments}

This article was originally published in Procedia Environmental Sciences, volume 29, in 2015. DOI:

10.1016/j.proenv.2015.07.210

A corrigendum correcting the misspelling of author Robert Walko's name was posted in November 2015 at DOI: 10.1016/j.proenv.2015.10.065.

\section{Creative Commons License}

\section{(c) (i) ()}

This work is licensed under a Creative Commons Attribution-Noncommercial-No Derivative Works 4.0 License.

\section{Copyright}

The authors

\section{Authors}

Seung Hee Kim, Jinwon Kim, Robert Walko, Boksoon Myoung, David Stack, and Menas Kafatos 


\title{
Climate Change Impacts on Maize-yield Potential in the Southwestern United States
}

\author{
Kim, Seung Hee ${ }^{\mathrm{a}, *}$, Jinwon Kim ${ }^{\mathrm{b}}$, Rovert Walko ${ }^{\mathrm{c}}$, Boksoon Myoung ${ }^{\mathrm{a}}$, David Stack ${ }^{\mathrm{a}}$, and \\ Menas Kafatos ${ }^{\mathrm{a}, \mathrm{d}}$ \\ ${ }^{a}$ Center of Excellence in Earth Systems Modeling and Observations, Chapman Univ., Orange, CA, USA, \\ ${ }^{b}$ University of California Los Angeles (UCLA), Los Angeles, CA, USA, \\ ${ }^{c}$ University of Miami, Miami, FL, USA, \\ ${ }^{d}$ School of Earth and Environmental Sciences, Schmid College of Science \& Technology, Chapman Univ., Orange, \\ CA, USA
}

\begin{abstract}
Agricultural productivity is strongly dependent on local climate conditions determined by meteorological parameters thus assessing the potential impact of the climate change and variability on regional agricultural systems has become crucial. To ensure food security, it is required to find under performing regions to investments and assess yields change in high-performing regions in coming decades under climate change and variability. In this study, we investigate the response of maize yield potential (Yp) on climate change scenario using Agricultural Production Systems sIMulator (APSIM) crop model over the Southwestern U.S. (SWUS) region.

APSIM's modules are essentially point-based models representing the system at a single point in space. We develop automated modeling framework (ApsimRegions, 2013), which allows the APSIM to be run over a large domain with about a thousand points over the study area. Using 21-year period (1991-2011) of North American Regional Reanalysis (NARR) data, we perform sensitivity test of the maize Yp to assess the relative contribution of climate variables, by adding standard deviation of the climatological values. The results show that maximum and minimum temperature greatly contribute to the variation of maize yields over the SWUS on the interannual time scale, depending on geographical locations with varied local climates.

In order to access data of present and future climate, we have completed high-resolution regional climate simulation by dynamically downscaling general circulation model results (GFDL-ESM2M) using regional climate models
\end{abstract}

\footnotetext{
* Corresponding author. Tel.: +1-714-289-3113; fax: +1-714-744-3491.

E-mail address: sekim@chapman.edu
} 
(WRF and OLAM). In this study, 20 years of integration period is selected in both historical period (1981-2000) and future period (2031-2050). The potential maize yields in the future period under the RCP8.5 greenhouse gas concentrations pathways show that the yields are significantly changed comparing to the historical period. In the generally rising temperature regime, the projected Yp shows strong geospatial variations according to the regional climate characteristics.

(C) 2015 The Authors. Published by Elsevier B.V This is an open access article under the CC BY-NC-ND license (http://creativecommons.org/licenses/by-nc-nd/4.0/).

Peer-review under responsibility of the organizing committee of the Agriculture and Climate Change - Adapting Crops to Increased Uncertainty (AGRI 2015)

Keywords: Regional climate change; yield potential; crop model; regional climate model; maize; Southwestern United States 